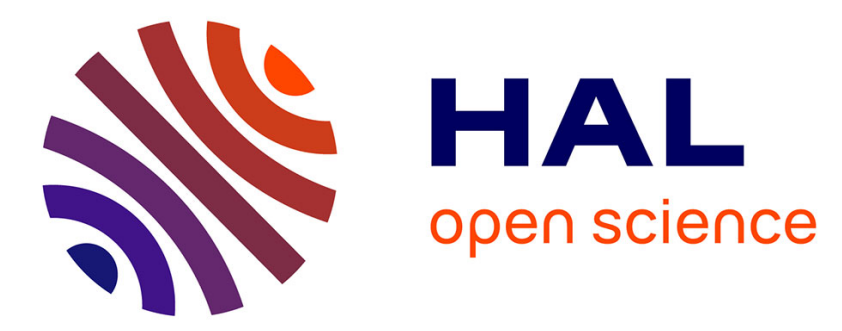

\title{
Microstructure and property of titanium heterogeneous laser welding
}

Laurent Weiss, Julien Zollinger, Pierre Sallamand, Eugen Cicala, Eric Fleury

\section{To cite this version:}

Laurent Weiss, Julien Zollinger, Pierre Sallamand, Eugen Cicala, Eric Fleury. Microstructure and property of titanium heterogeneous laser welding. 13th World Conference on Titanium, 2015, San Diego, United States. pp.317-321, 10.1002/9781119296126.ch48 . hal-02455036

\section{HAL Id: hal-02455036 https://hal.science/hal-02455036}

Submitted on 25 Jan 2020

HAL is a multi-disciplinary open access archive for the deposit and dissemination of scientific research documents, whether they are published or not. The documents may come from teaching and research institutions in France or abroad, or from public or private research centers.
L'archive ouverte pluridisciplinaire HAL, est destinée au dépôt et à la diffusion de documents scientifiques de niveau recherche, publiés ou non, émanant des établissements d'enseignement et de recherche français ou étrangers, des laboratoires publics ou privés. 


\title{
MICROSTRUCTURE AND PROPERTY OF TITANIUM HETEROGENEOUS LASER WELDING
}

\author{
Laurent Weiss $^{1,2}$, Julien Zollinger ${ }^{2,3}$, Pierre Sallamand ${ }^{4}$, Eugen Cicala ${ }^{4}$ and Eric Fleury ${ }^{1,2}$ \\ ${ }^{1}$ LEM3, Université de Lorraine, Ile du Saulcy, 57000 Metz, France \\ ${ }^{2}$ Laboratory of Excellence for Design of Alloy Metals for Low-mass Structures ('DAMAS' Labex), Université de Lorraine, France \\ ${ }^{3}$ Institut Jean Lamour, Université de Lorraine, Parc de Saurupt, 54011 Nancy, France \\ ${ }^{4}$ Laboratoire Interdisciplinaire Carnot de Bourgogne, Université de Bourgogne, 12 rue de la fonderie, 71200 Le Creusot, France
}

Keywords: Laser heterogeneous welding; Tensile test; Microstructure;

\begin{abstract}
Dissimilar welding has been investigated for three different couples of titanium alloys: $\alpha / \alpha+\beta, \alpha / \beta$ and $\alpha+\beta / \beta$. Plates of $100 \mathrm{x}$ $60 \times 1.6$ or $1.8 \mathrm{~mm}$ were welded with a Yb:YAG laser. Tensile tests show that the properties of the dissimilar welded specimens were generally controlled by those of the weakest material except for the $\alpha+\beta / \beta$ where the ultimate tensile strength was approximately equal to the average value of both materials. In every case, the welding sample elongation was found to be smaller than that of the base metals. The rupture took place away from the bead and was found to be always located in the alloy having the lowest mechanical properties. Nevertheless, a few large-size pores detected by tomography in the $\alpha+\beta / \beta$ couple could explain why rupture for these samples occurred in the weld bead. For each couple, the porosities were situated at the board between the heat affected zone and the molten zone. EBSD map and EDX enabled the observation of different microstructures, which could be correlated to the heterogeneous composition and diffusion into the melted bath.
\end{abstract}

\section{Introduction}

The welding of titanium alloys has recently received many interests, particularly in aeronautics and it is expected that welded components even of the class 1 could be integrated in the future commercial airplanes. In aviation, each part of the components does not necessarily need to withstand the same mechanical stress, the same corrosion or the same working temperature. Nevertheless, for standardization purpose, the pieces are made of the same alloy and are often oversized compared to the actual need. Some papers report studies about heterogeneous titanium welding such as Ti-Al $[1,2]$ Ti-steel $[3,4]$ or Ti-Mg $[5,6]$ but a few only are dealing about Ti-Ti welding. Wang et al. [7] has shown that the characteristics of dissimilar Electron Beam Welding (TA6V and BT9) were comprised of $\alpha^{\prime}$ martensite in the HAZ (Heat Affected Zone) and FZ (Fusion Zone) with properties close to the alloy with the lower mechanical properties. According to Ferdinand [8], for 21S and Ti6242 alloys, the widths of welds prepared by laser were lower than those obtained by TIG welding, and the mechanical properties were found to be superior. To complete the knowledge, we have selected three different titanium alloys commonly used in aeronautics, each alloy having its own qualities: pure titanium $\mathrm{T} 50 \mathrm{~A}$ is the cheapest and has the best ductility, TA6V has excellent mechanical strength/density ratio as to $\beta-21 \mathrm{~S}$ is the alloy having the greater resistance to oxidation/corrosion at high temperature. Their properties are the consequence of their different composition and structure: pure $\alpha$ for T50A, $\alpha+\beta$ for Ti-6Al-4V (TA6V) and pure $\beta$ for Ti-15Mo$3 \mathrm{Al}-2.7 \mathrm{Nb}-0.2 \mathrm{Si}(\beta-21 \mathrm{~S})$. These alloys were butt welded under various welding processing parameters using a Yb:YAG laser. An experimental design was defined based on variation of the parameters such as the displacement velocity $(v)$, power $(P)$ and the and beam offset from the joint line $(\Delta x)$. The aim is to relate the change in the microstructure and properties to the processing conditions, and to propose procedures to improve the performance of the welded joints. The microstructure of the beads was analyzed by optical and Secondary Electron Microscopy (SEM) equipped with an Electron Back-Scattered Diffraction (EBSD), and the chemical composition by Energy Dispersive X-ray spectroscopy (EDX). Tensile tests were performed to study the mechanical properties. The presence of porosities was confirmed by X-ray tomography.

\section{Material and Experimental Setup}

Thin sheets were purchased from TIMET Company of 1.6, 1.8 and $1.83 \mathrm{~mm}$ thicknesses for the Ti50A, TA6V and $\beta-21 \mathrm{~S}$ (referred as 21S), respectively. Those sheets were cut by water jet cutting to obtain $60 \times 100 \mathrm{~mm}$ rectangular plates, which were then butt welded to form three couples: Ti50A/TA6V, Ti50A/21S and TA6V/21S. The welding experiments were carried out in a keyhole mode using by Yb:YAG laser (TRUMPF laser) with maximal beam power of $6 \mathrm{~kW}$ and spot diameter of $600 \mu \mathrm{m}$. The laser beam was focused at top surface. Argon was used as top and bottom shielding gas with flow rate of $20 \mathrm{l} / \mathrm{min}$. The experimental design plan has been applied to study the effect of power $(2,2.5,3$ $\mathrm{kW})$, working speed $(2,2.5,3 \mathrm{~m} / \mathrm{min})$ and beam offset from the joint line $(-0.3,0$ and $0.3 \mathrm{~mm})$. Preliminary tests were performed to find the better parameters and to limit the experimental design. Plates were cleaned with acetone before welding.

Tensile test specimens were extracted perpendicularly to the weld bead by means of water jet cutting to keep the microstructure intact without temperature impact. The tensile test experiments were performed on the heterogeneous and homogeneous welded plates in the as-welded state and completed by tests on the base alloys with an Instron tensile test machine under an initial strain rate of $0.01 \mathrm{~s}^{-1}$. Defects were detected by tomography analyses using a EasyTom Nano Tomograph (RXSolutions) with a spatial resolution equal to $4 \mu \mathrm{m}$ when the studied bead length is $5 \mathrm{~mm}$. The reconstructions were performed with $\mathrm{X}$-Act software.

The macrographic analysis was performed with an optical microscope Olympus BX61 and reconstruction multimaping with Stream Motion software. The microscopic images were taken on 
two different Scanning Electron Microscopes (SEM): a JEOL JSM-6490 (with a W-gun emitter) and a Zeiss Supra 40 (with a Schottky field emission emitter). Grain orientations were determined by EBSD, using AZtech (Oxford Instruments, HKL Technology) for data acquisition and the chemical composition using Esprit Software (Brüker).

\section{Experimental Results}

For comparison, the stress-strain curves of the base materials under uniaxial tensile tests are plotted in Fig. 1, 2 \& 3 together with those obtained for the dissimilar welding assemblies. The T50A alloy displayed the largest elongation and the TA6V the highest strength. Despite the characteristics of these base materials, the T50A-TA6V couple presented the lowest performances in term of ductility. The hardening in the strainstrain curve and the elongation at fracture were similar to those of the TA6V-TA6V while the value of the ultimate tensile stress corresponded to that of the T50A. As described above for the T50A-TA6V, the properties measured for the T50A-T21S dissimilar couple were significantly reduced in comparison to those of the parent alloys. The form of the stress-strain curve for the T50A-T21S dissimilar welding was totally different than the $21 \mathrm{~S}$ in the plastic zone. Nevertheless, we can note that the homogeneous $21 \mathrm{~S}-21 \mathrm{~S}$ couple preserved the same characteristics than those of the $21 \mathrm{~S}$ parent material. The TA6V-21S couple displayed the best performances in terms of both elongation and strength. This dissimilar welding enabled to preserve the advantage of both alloys: higher strength resistance in comparison to the $21 \mathrm{~S}$ and larger value of elongation to rupture in comparison to TA6V. The form of stress-strain curve for the dissimilar welding is nearly identical to that of the pure $21 \mathrm{~S}$.

For all dissimilar welding assemblies, the failure always took place away from the bead, and in the material having the lowest properties. This result demonstrates the quality of the joints (figure 4). Nevertheless it should be noted that, for the couple TA6V/21S, nearly $40 \%$ of the specimens have broken in the middle of the welded zone.

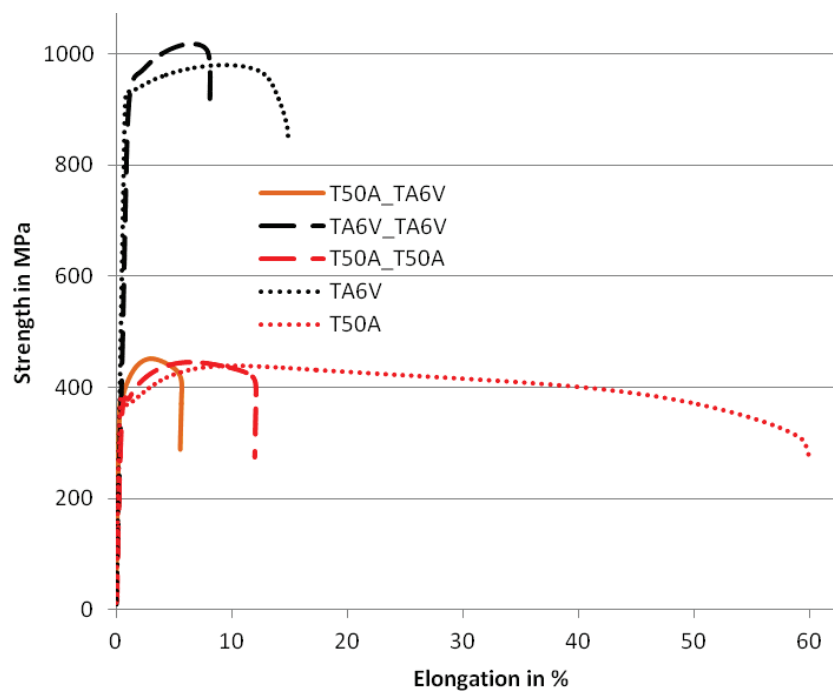

Figure 1: Tensile test of T50 A/TA6 V couple $(P=2.5 \mathrm{~kW}, v=2.5$ $\mathrm{m} / \mathrm{min}, \Delta x=0$ )

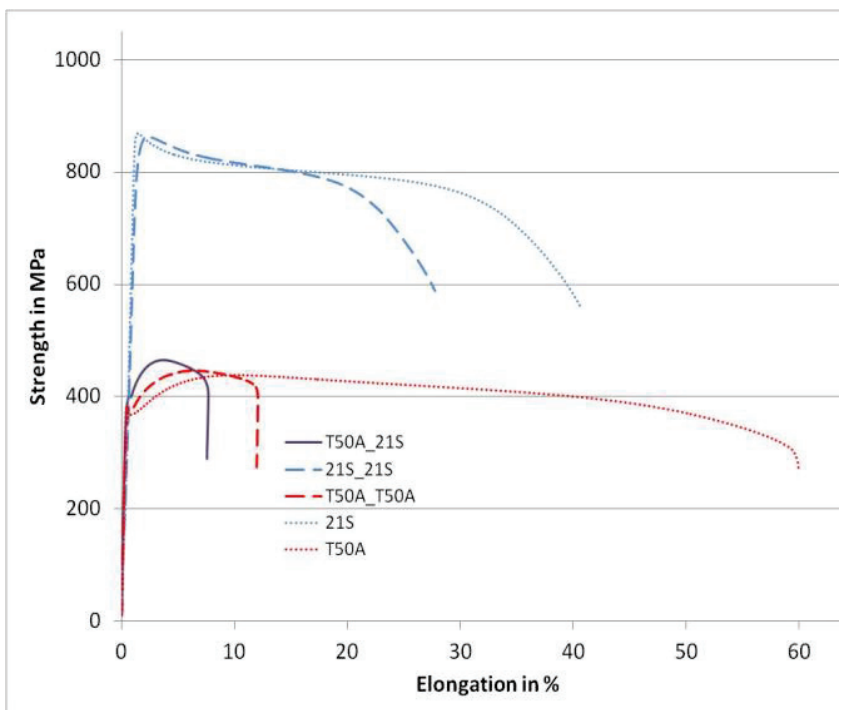

Figure 2: Tensile test of T50 A/21S couple $(P=2.5 \mathrm{~kW}, v=2.5$ $\mathrm{m} / \mathrm{min}, \Delta x=0$ )

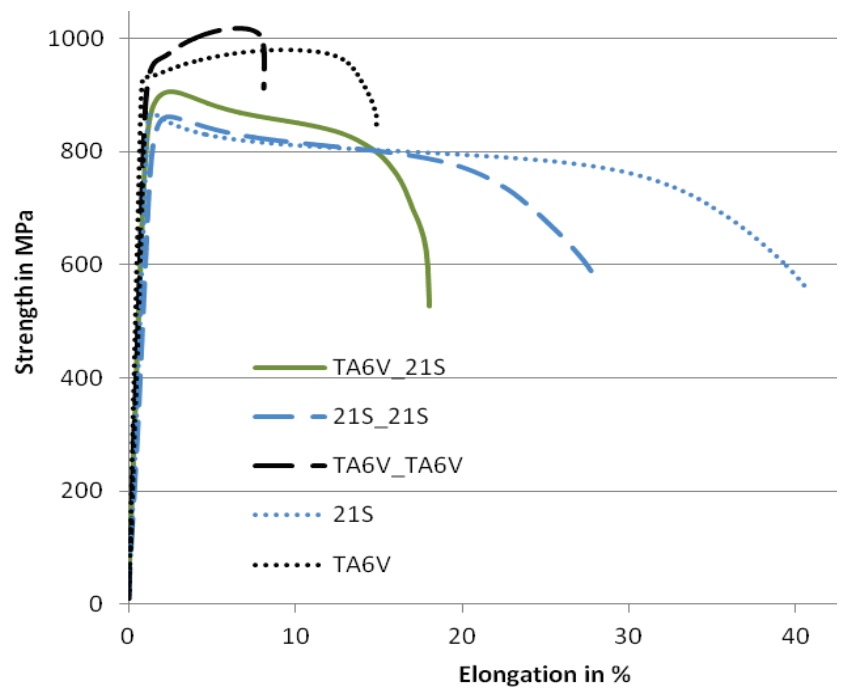

Figure 3: Tensile test of TA6 V121S couple $(P=2.5 \mathrm{~kW}, v=2.5$ $\mathrm{m} / \mathrm{min}, \Delta x=0$

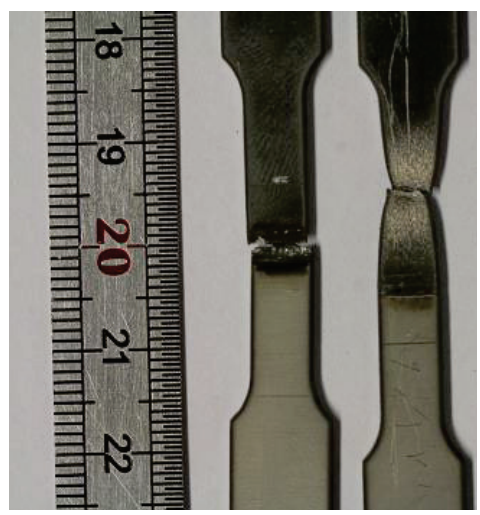

Figure 4: Two tensile test specimen of TA6VI21S after break 
If we observe the fracture surface with SEM (Figure 5), we note the presence of porosities, which are critical locations for strain concentration area and crack initiation.

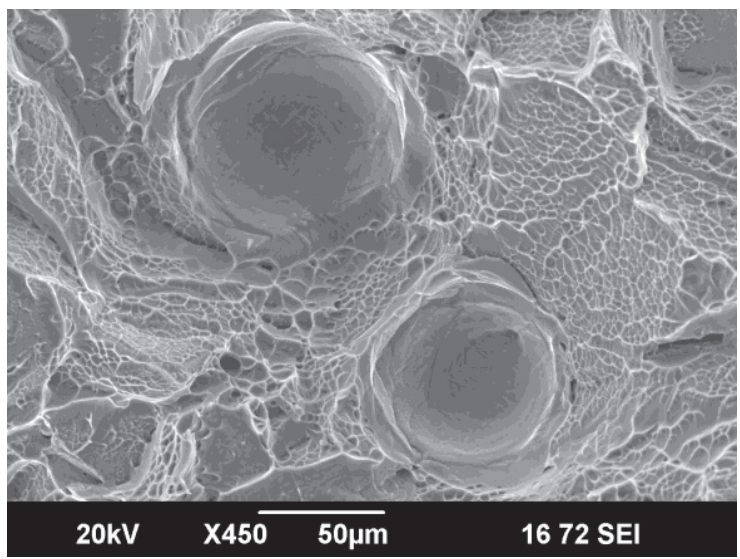

Figure 5: Porosity at the fracture surface of TA6V/21S

These unexpected fractures could be explained by the presence of a few porosities of large diameter (up to $100 \mu \mathrm{m}$ ) as shown in the tomographic reconstruction (Fig. 6) while porosities detected in the other couples were not as large (less than $30 \mu \mathrm{m}$ ).

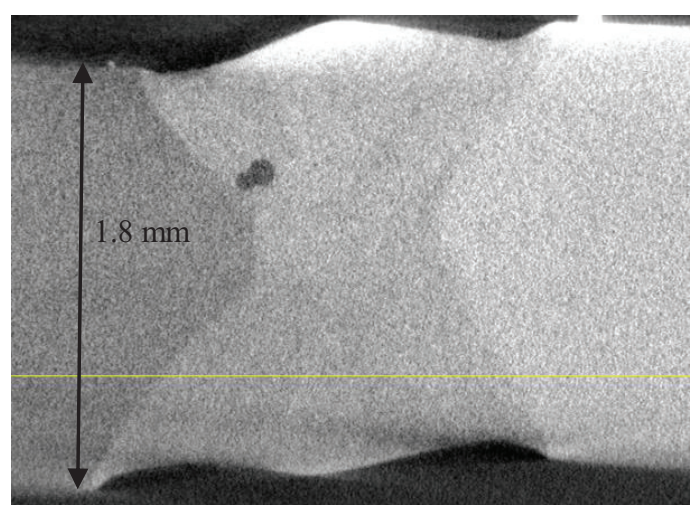

Figure 6: Porosity in the TA6V/21Sbead $(P=3 \mathrm{~kW}, v=3 \mathrm{~m} / \mathrm{min}$ and $\triangle x=0 \mathrm{~mm}$ )

An interesting fact is these large pores are always located close to the interface between the HAZ and the FZ. Porosities can be on the whole height of the cord but were mainly located towards the center. This phenomenon has already been observed and it has been explained by both different physical aspects: the limit of gas solubility and the convective movements of the molten metal [9]. The pores are principally the consequence of the presence of hydrogen in the base metal (14-42 ppm). The gas solubility limit in the molten metal increases with the decrease of the temperature and drops abruptly at solidification. The bubble nucleation takes place at the surface of solid metal (HAZ). Hydrogen comes either from the solid or from the liquid center (where the temperature is hotter so the diffusivity is lower) and grows the bubbles. As function of convection dynamic these bubbles can diffuse to the surface and escape to the atmosphere. For electron beam or arc welding, the lower is the displacement velocity of the source, the lower is the porosity density because the bubbles have enough time to reach either the top or bottom surface of the FZ. In our case, the couples containing $21 \mathrm{~S}$ present large porosities with the largest detected for TA6V/21S. The proposed explanation is the viscosity of the bath, which is much higher because of the Mo and $\mathrm{Nb}$ alloying elements in the 21S. Bubbles formed but are believed to hardly move in the liquid. The short travel distance only allowed them to coalesce and, finally, to grow. Their location can be explain by two ways: nucleation and growth at HAZ/FZ edge and, on another hand, by an ease of movement along the solid wall. Further experiments and models should be done to explain completely the formation of the porosities.

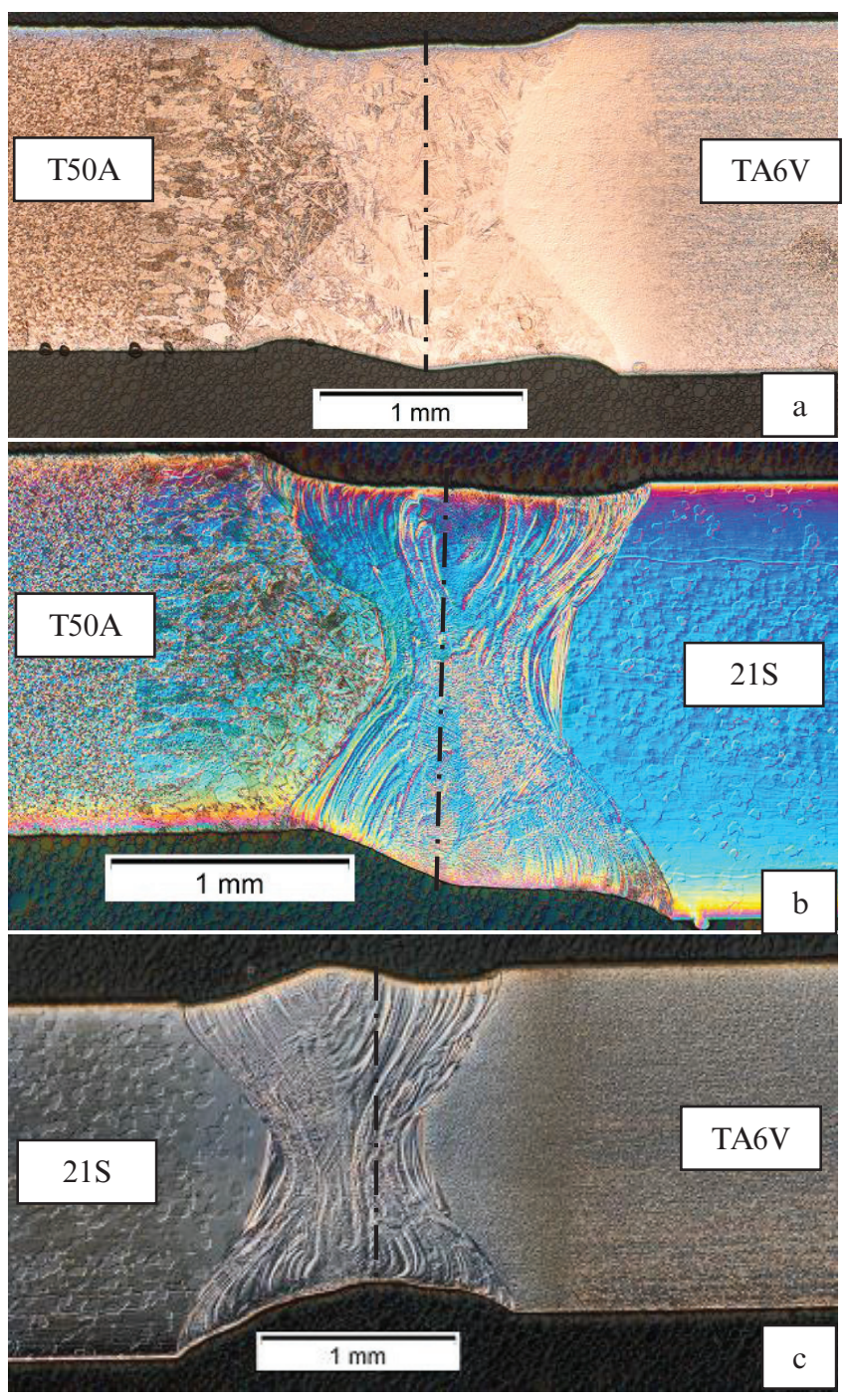

Figure 7: Optical micrographies of: a. T50A/TA6 V, b. T50A/21S and c. TA6 VI21S $(P=3 \mathrm{~kW}, v=3 \mathrm{~m} / \mathrm{min}, \Delta x=0)$. The dotted line represents the initial joint plane

The as-received sheets present $\alpha$ equiaxed grains for T50A, $\beta$ equiaxed grains for $21 \mathrm{~S}$ and inter-granular $\beta$ phase in an equiaxed $\alpha$ phase for TA6V. Optical micrographs of different couples (Fig. 7) show different microstructures in the HAZ and FZ. For T50A, just after the limit with the base metal, the HAZ presented very large $\alpha$ grains, which changed into a mixture of $\alpha$ and $\alpha^{\prime}$. This alloy had the larger HAZ due to the high thermal conductivity (21.79, 6.60 and $7.60 \mathrm{~W} / \mathrm{m} . \mathrm{K}$ for T50A, TA6V and 21S respectively). The HAZ on the TA6V side was a mixture of small 
grains composed by $\alpha$ and $\alpha^{\prime}$ in a $\beta$ matrix. The volume of $\alpha$ phase increased with the distance from the FZ. The microstructure of in the HAZ on the $21 \mathrm{~S}$ side appeared to be similar to that of the base metal because this alloy contains a high fraction of $\beta$ stabilizer elements and thus is not affected by heat.

The FZ of the T50A/TA6V couple was found to be formed by acicular $\alpha^{\prime}$ due to the rapid cooling rate but the boundaries of the prior $\beta$ grains still easily visible after etching. The couples with $21 \mathrm{~S}$ keep a very large grains $\beta$ phase at room temperature due to its chemical composition. Moreover, in the case of the 21S, the motion lines of the liquid bath are visible in these micrographs.
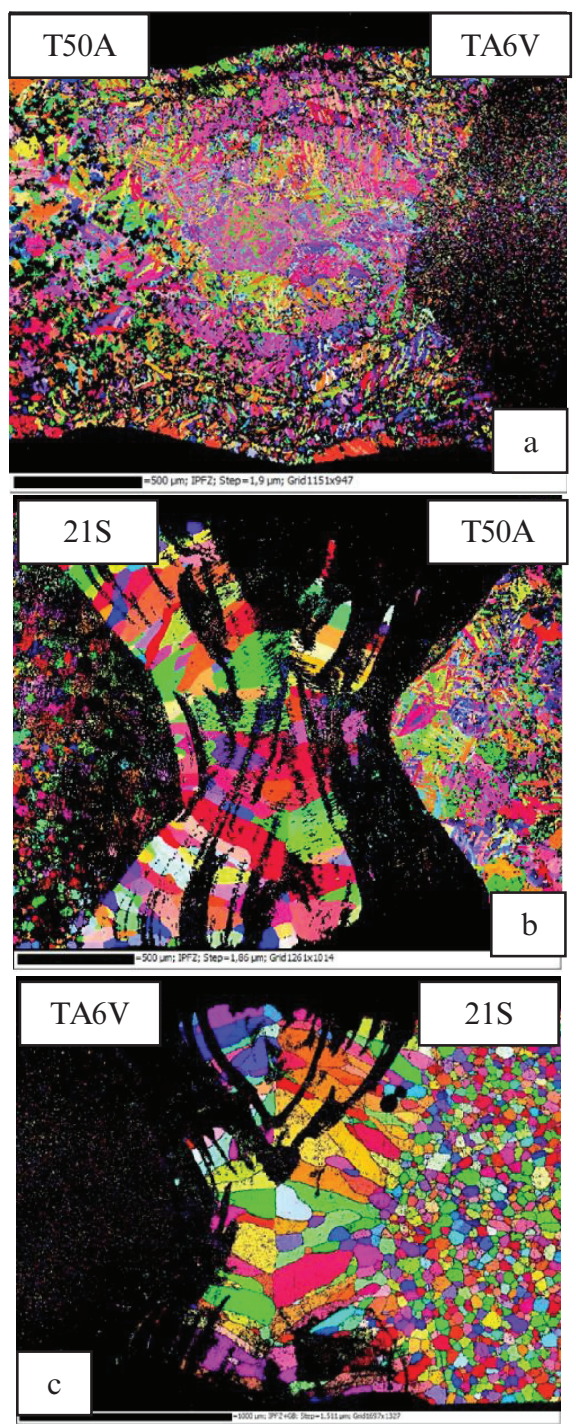

Figure 8: EBSD Map of : a. T50A/TA6V, b. T50A/21S and c. TA6 VI21S $(P=3 \mathrm{~kW}, v=3 \mathrm{~m} / \mathrm{min}$ and $d=0 \mathrm{~mm})$

EBSD map showing the grains form are given in the figure 9. Unindexed areas (black color) are the result of a distorted microstructure in the HAZ and FZ. We can note that, in the FZ, those areas are situated in the $21 \mathrm{~S}$ couples in the side of the other alloy. Further experiments are in progress to investigate these microstructures. We can note that the $\beta$ grains grow up to the center of the bead and form a vertical joint easily visible in the figure 9.c. As shown by the calculated values reported in Table 1, the various titanium alloys have quite neighboring liquidus temperatures. In addition, the solidification intervals are small, i.e., the largest value being equal to $91{ }^{\circ} \mathrm{C}$ for the TA6V, which was calculated with the Scheil template.

These two points show that for small solidification interval, it really heat that controls the growth (rather than chemical) and, as a consequence, this heat is similar in both materials, or in any case in the ZF. That is why the $\beta$ grains grew at the same times in the both parts of the FZ and met at the middle to form a vertical grain boundary.
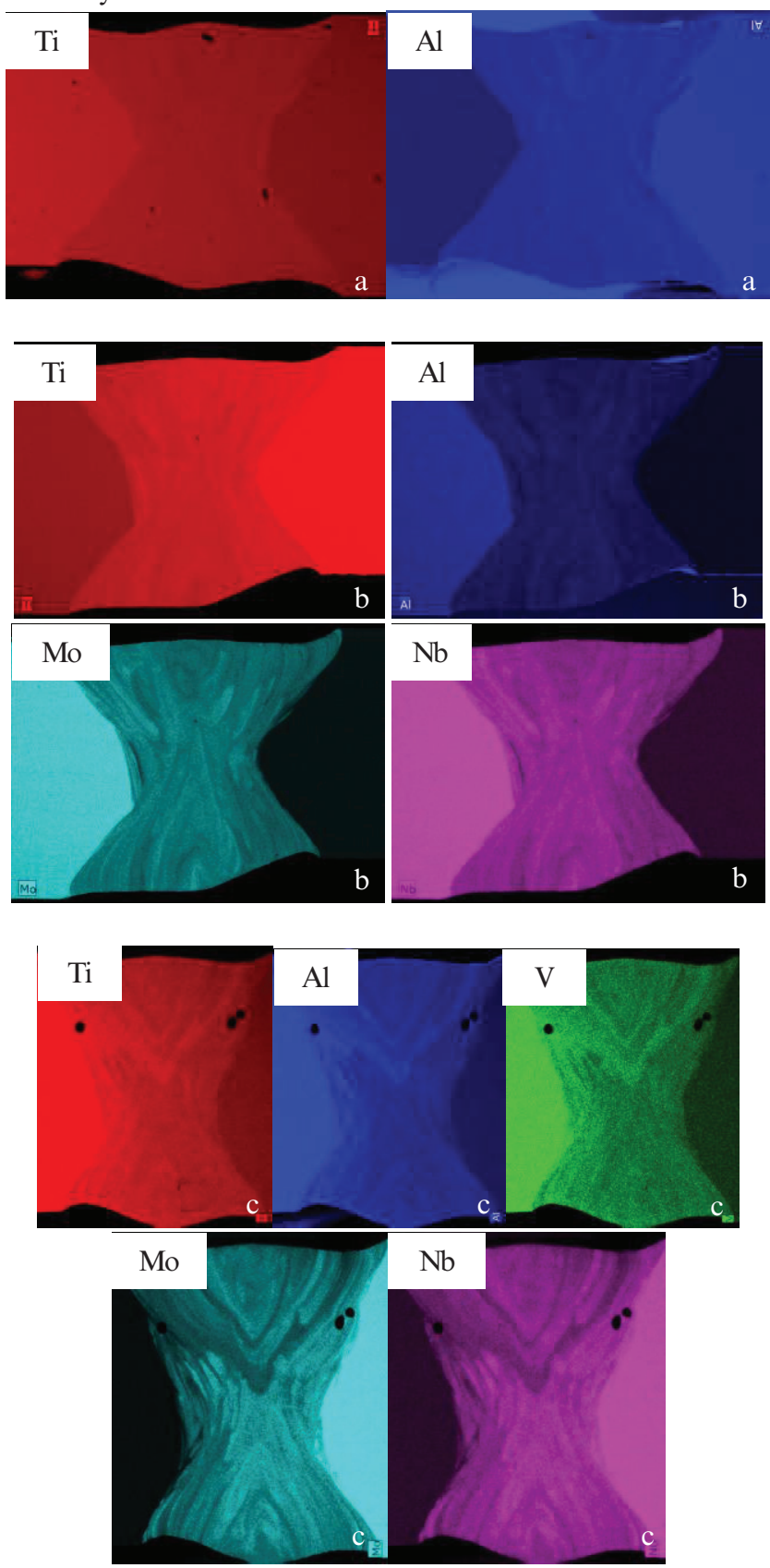

Figure 9: EDX Map of : a. T50A/TA6V, b. 21S/T50A and c. TA6 VI2 $1 \mathrm{~S}(P=3 \mathrm{~kW}, v=3 \mathrm{~m} / \mathrm{min}$ and $d=0 \mathrm{~mm})$ 


\begin{tabular}{|c|c|c|c|c|}
\hline Alloy & $\mathrm{T}_{\text {Liq }}$ & $\mathrm{T}_{\text {sol }}$ & $\Delta \mathrm{T}$ (eq.) & $\Delta \mathrm{T}$ (Sch.) \\
\hline T50 & 1665 & 1655 & 10 & 80 \\
\hline TA6V & 1704 & 1698 & 6 & 39 \\
\hline $21 \mathrm{~S}$ & 1751 & 1725 & 26 & 91 \\
\hline
\end{tabular}

Table 1: Liquidus and solidus temperatures, and solidification range in equilibrium and with the Scheil model. Temperature are given in degrees Celsius. Calculations made with thermocalc and the TTTi3 database.

EDX qualitative map (Fig. 9) can be correlated to the EBSD map (Fig. 8). The first observation is that the EBSD unindexed areas are those containing the most $\alpha$ stabilizer element such as aluminum. So these zones could be very small, thin and chaotic $\alpha^{\prime}$ needles but more experiments are required and are currently in progress in order to confirm. In addition, the second observation is that the different alloys did not mix in the fusion zone, so that means the interdiffusion is weak and creates macro segregation bands. This phenomenon is believed to result from the consequence of the different viscosities of the melt. This fact explains the presence of the heaviest elements of the couples at the bottom side of the weld bead. Moreover, the porosities were easily visible and did not seem to be in a particular chemical zone. About the welding conditions, we have noted that the higher is the power and the lower is the speed, the larger is the width of the bead regardless of the couple. Furthermore, the welds prepared with $\Delta x=0 \mathrm{~mm}$ displayed the best ductility as shown in figure 10 .

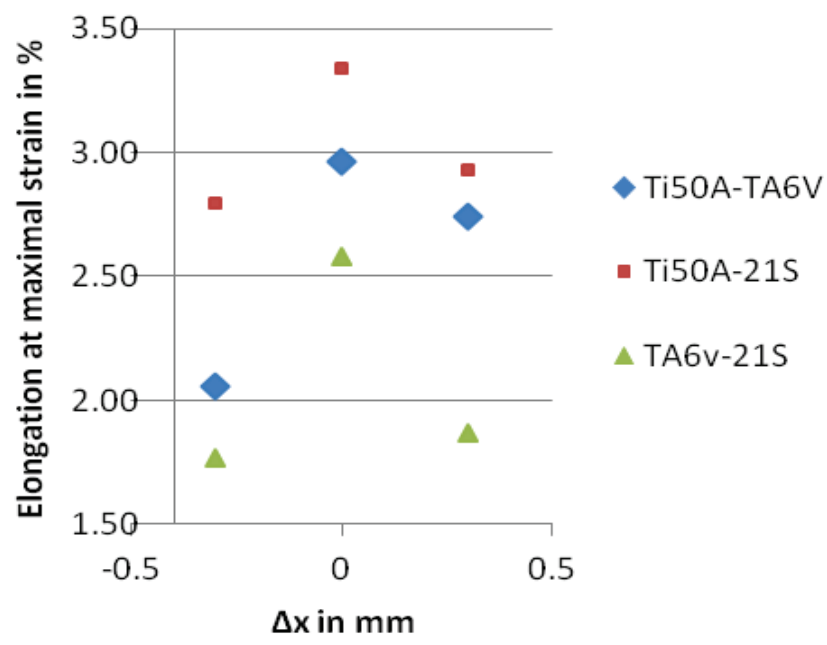

Figure 10: Elongation at maximal strain as function as beam offset from the joint line $(P=2.5 \mathrm{~kW}$ and $v=2.5 \mathrm{~m} / \mathrm{min})$

\section{Conclusions}

Various dissimilar titanium laser welding has been performed with three different alloys: T50A, TA6V and 21S. The experiments show that :

- Heterogeneous welding beads with T50A have lower mechanical properties due to the martensitic transformation while the TA6V/21S have the higher capacities.

- The couples containing $21 \mathrm{~S}$ presented large chemical segregations as a consequence of the addition elements that increased the viscosity of the melted zone.
- Large porosities formed during the welding process for couple containing $21 \mathrm{~S}$ because the gas could not escape from the FZ owing to the difference in the viscosity of both alloys. These large porosities were detected at the limit of the HAZ/FZ.

- Our results indicated that a small beam offset from the joint line reduced the mechanical properties.

\section{Acknowledgments}

This research has been funded by the Laboratory of Excellence for Design of Alloy Metals for Low-mass Structures ('DAMAS' Labex). The authors would like to thank Eng. Patrick Moll and Mélanie Duband for their help during the experiments.

\section{References}

1. Y.C Chen and K. Nakata, Microstructural characterization and mechanical properties in friction stir welding of aluminum and titanium dissimilar alloys, Materials \& Design, 30, 3, (2009) 469474

2. U. Dressler, G. Biallas, and U.A. Mercado, Friction stir welding of titanium alloy TiAl6V4 to aluminium alloy AA2024-T3, Materials Science and Engineering: A, 526, 1-2, (2009), 113-117 3. N. Kahramana, B. Gülença, F. Findik, Joining of titanium/stainless steel by explosive welding and effect on interface, Journal of Materials Processing Technology, 169, 2, (2005), 127-133

4. U. Kamachi Mudali et al., Corrosion and microstructural aspects of dissimilar joints of titanium and type 304L stainless steel, Journal of Nuclear Materials, 321, 1, (2003), 40-48

5. R. Borrisutthekul, Y. Miyashita and Y. Mutoh, Dissimilar material laser welding between magnesium alloy AZ31B and aluminum alloy A5052-O, Science and Technology of Advanced Materials, 6, 2, (2005), 199-204

6. M. Gao et al, Laser Keyhole Welding of Dissimilar Ti-6Al-4V Titanium Alloy to AZ31B Magnesium Alloy, Metallurgical and Materials Transactions A, 43, 1, (2012) 163-172

7. S.Q. Wang, J.H.Liu and D.L.Chen, Tensile and fatigue properties of electron beam welded dissimilar joints between $\mathrm{Ti}-$ 6. $\mathrm{Al}-4 \mathrm{~V}$ and BT9 titanium alloys, Materials Science \& Engineering A, 584, (2013) 47-56

8. C. Ferdinand, Mise en oeuvre et caracterisation d'assemblages soudés par procédés TIG et laser de tôles d'alliages de titane refractaire, Implementation and characterization of welded joints by TIG and laser processing sheets of refractory titanium alloys, $\mathrm{PhD}$ thesis, (2005), INPT, France, (in French)

9. T. Mohandas, D. Banerjee and V.V. Kutumba Rao, Fusion Zone Microstructure and Porosity in Electron Beam Welds of an $\alpha$ $+\beta$ Titanium Alloy, Metallurgical and Materials transactions A, 30A, (1999) 789-798 
